Indexed by

\title{
Scopus
}

\section{DESIGNING A TOOL FOR COLD KNURLING OF FINS}

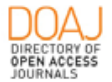

Crossref

OOBSON

81'Google

\section{Andrej Olejnik}

Moscow State Technological

University "Stankin",

Institute of Information Systems

and Technologies, Department

of Management and Informatics

in Technical Systems

Moscow, Russia

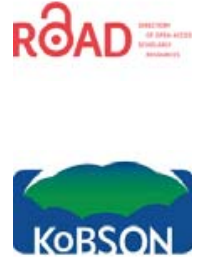

Aslan Tatarkanov

Institute of Design-Technology

Informatics of the Russian

Academy of Sciences,

Moscow, Russia mation of the metal

doi:10.5937/jaes18-25786
Alexey Kapitanov

Moscow State Technological

University "Stankin",

Department of Automated

Information Processing and

Control Systems,

Moscow, Russia

\section{Islam Alexandrov}

Institute of Design-Technology Informatics of the Russian

Academy of Sciences,

Moscow, Russia

Key words: inner surfaces, cold knurling of fins, knurling tool, spiral fins, screw fins, plastic defor-

Cite article:

Olejnik, A., Kapitanov, A., Alexandrov, I., \& Tatarkanov, A. [2020]. Designing a tool for cold knurling of fins. Journal of Applied Engineering Science, 18(3), 305 - 312.

Online aceess of full paper is available at: www.engineeringscience.rs/browse-issues 


\title{
DESIGNING A TOOL FOR COLD KNURLING OF FINS
}

\author{
Andrej Olejnik ${ }^{1 *}$, Alexey Kapitanov ${ }^{2}$, Islam Alexandrov ${ }^{3}$, Aslan Tatarkanov ${ }^{3}$ \\ ${ }^{1}$ Moscow State Technological University "Stankin", Institute of Information Systems and Technologies, \\ Department of Management and Informatics in Technical Systems Moscow, Russian Federation \\ ${ }^{2}$ Moscow State Technological University "Stankin", Department of Automated Information Processing and \\ Control Systems, Moscow, Russian Federation \\ ${ }^{3}$ Institute of Design-Technology Informatics of the Russian Academy of Sciences, Moscow, \\ Russian Federation
}

Regulating the deformed metal's flow is an important condition for the knurling process. To achieve this, the knurling tool should have a special intake part, where all the main work of plastic deformation would be realized. Depending on the configuration, the fins can be knurled in two ways: either by a radial feed of the tool or an axial feed of a billet (package of billets) or a tool. Using the radial feed method, most types of piece gear parts can be knurled using a more rational radial flow of the deformed metal. However, this process is usually characterized by low productivity. The axial knurling method is significantly more productive. In this case, due to the undesirable axial flow of the deformed metal, it flows to the ends of the billets. As a result, it becomes necessary to introduce additional machining operations and metal waste increases. The article provides an analysis of existing methods of forming fins on a cylindrical surface. The authors analyze the advantages and disadvantages of applying the methods in modern conditions, select the most appropriate method, and substantiate the principles of developing tools for cold knurling of fins. The purpose of the work was to develop a tool for determining the forces acting in the cold knurling process and study their influence on the characteristics of the final products.

Key words: inner surfaces, cold knurling of fins, knurling tool, spiral fins, screw fins, plastic deformation of the metal

\section{INTRODUCTION}

One of the most progressive directions in the development of modern engineering is the desire to reduce the specific gravity of machining and to obtain a billet approaching in shape and size to the finished product [1-3]. This is largely due to a decrease in the relative role of subtractive technologies for processing materials by cutting due to the development of additive and hybrid technologies of shaping, the development of pressure processing methods $[4,5]$. Given this thesis, engineers and technologists face many unsolved problems associated with increasing the efficiency and productivity of solutions, while reducing and minimizing implementation costs.

One of the applied problems that need to be solved in the key to increasing the efficiency of the technological process while improving the quality of products is the production of developed heat transfer surfaces with a decrease in overall dimensions. Today, compact and efficient heat transfer tools include products with transverse finned surfaces - finned tubes [6]. Executions of transversely finned surfaces differ in manufacturing technology and in geometric, mass, thermo-physical and thermo-aerodynamic parameters [7, 8]. Cross-finned pipes are produced by the following methods: special casting methods [9-11], installing or rolling on alongside with brazing spiral-ribbon fins [12], pressing the fins along the guide $[13,14]$, knurling bimetallic (aluminum and copper) fins on a steel supporting pipe [15-17], electric arc or high frequency currents (HFC) welding of fins [18]. In the case of cold knurling of finned surfaces, the axial, radial, and circumferential components of the cold knurling force have a significant effect on the nature of the deformed metal flow. The purpose of this work was to develop a tool for determining the forces acting in the cold knurling process and study their influence on the characteristics of the final products.

The types of finned tubes with the highest manufacturability have been introduced massively, the manufacture of which is possible in mass production on highly efficient and technologically advanced equipment - these are tubes with finned non-ferrous metals and alloys pressed into a spiral groove (aluminum, copper), bimetallic tubes with spiral-screw finning, as well as pipes with spiral-screw fins welded using high-frequency currents [1719]. At the same time, these types of finned pipes have significant technological and operational shortcomings, namely low thermal and diffusion contact of the fins with the supporting pipe and the high cost of metals and alloys used for the first two types in production, low degree of surface development (reduced finning coefficient), as well as the high complexity and cost of production equipment of automatic lines for fins of pipes with spiral-helical welded fins. The estimated cost per linear meter of finned tubes can reach 20 or more US dollars, which reduces the competitiveness and potential of their mass and serial production. The increased cost and energy intensity of the corresponding production and technological equipment does not make it possible to increase production 
capacities and the necessary output volumes.

Products manufactured by these enterprises have many significant structural and operational advantages. In particular, they have reduced aerodynamic drag in comparison with round pipes, which makes it possible to reduce production and operation costs, and produce designs in which movement of inter-fin and annular airis carried out by natural traction [20-23]. However, the technology involved in manufacturing this type of finned pipe is expensive; it is high in energy consumption and production is relatively slow. This can be associated with either the electromechanical winding of spiral-ribbon fins or the installation of rectangular fins on an oval-section supporting pipe and subsequent brazing to a support pipe by immersion in molten zinc [24].

\section{LITERATURE REVIEW}

Modern production has various technological processes at its disposal, aimed at connecting with subsequent affixing of the fins to the outer surface of the supporting pipe. These processes have both positive and negative qualities [6-8]. The gradation of methods for producing fins based on patent searches (on patent documentation funds) allows us to distinguish the following groups: obtaining fins by precision casting; winding with a pretension of a non-ferrous metal tape (usually aluminum) onto a supporting alloyed base in the form of a steel pipe; crimping steel washers on a supporting pipe; continuous arc or resistance welding of steel tape or washers; and connection of the fins of steel pipes with high-frequency currents [9, 10, 12, 14, 18].

Existing methods, in turn, can be differentiated into the following subclasses: finning, mechanical finning [25]; and fins obtained using welding methods (arc, contact, or high-frequency currents) [18]. As a basis, steel or cast-iron pipes are more often used as a supporting pipe, less commonly used non-ferrous metals. To aid heat transfer from the coolant in contact with the carrier pipe to the surrounding space (through the developed fin surface to the outer surface of the carrier pipe), fins are fixed transversely or longitudinally. The fins are mainly made of aluminum and copper and less often of brass and carbon steel. Along with this, the following types of manufacturing can be distinguished:

1. Use of a solid billet. This involves the use of special casting methods or the extrusion method from a solid billet $[10,26,27]$. Products made by this method have enhanced operational properties and durability because there is no diffusion connection between the fins and the supporting tube. However, despite its positive qualities, this manufacturing type is expensive and technologically complex. Consequently, it is not widely used.

2. Using a composite billet. This type involves using two metals when manufacturing finned tubes and using the thermos-physical properties of each metal to improve the technical characteristics of the final product. The combination of a high level of thermal conductivity and mechanical strength leads to an increase in the anticorrosion and performance properties of the final product. A material, preferably carbon or stainless steel, is selected as the basis for the carrier pipe considering physico-mechanical and temperature characteristics. The most effective material for making a finned surface is copper, which has high heat transfer properties, though aluminum is more economically efficient, having thermal properties comparable to copper [6].

Worldwide, many enterprises, multi-unit enterprises, and factories produce finned pipes. Many industries that manufacture finned tubes for heat exchangers use the high-frequency currents (HFC) method [18]. However, this method has many operational and technological disadvantages:

1. Process speed: The process speed is much higher relative to other manufacturing methods, but modern economic development and market conditions require scaling and an increase in output. In the process used, increasing productivity is a difficult task.

2. Energy consumption. The consumption of technological and production equipment used in the manufacture of the HFC method is estimated at $264 \mathrm{~kW}$. When using a pipe with a diameter of $30 \mathrm{~mm}$ and a rotation speed of $200 \mathrm{rpm}$, the production speed is $3.79 \mathrm{~m} / \mathrm{min}$, which corresponds to a welding speed of $0.49 \mathrm{~m} / \mathrm{s}$. Thus, more than $1.25 \mathrm{~kW} / \mathrm{h}$ is required per $1 \mathrm{~m}$ of a finned pipe. Finned pipes are mass-produced; therefore, the energy consumption with this method at $1.25 \mathrm{~kW} / \mathrm{h}$ is estimated as extremely high.

3. Restriction on materials. The HFC method is not optimized for the use of various types of metals, as it is a special solution for steel fins (support pipe is made of steel; fins are made of steel tape). Steel is not the perfect material for heat transfer. In terms of heat transfer, the use of steel and steel alloys is not the

$\Delta h, \mathrm{MM}$

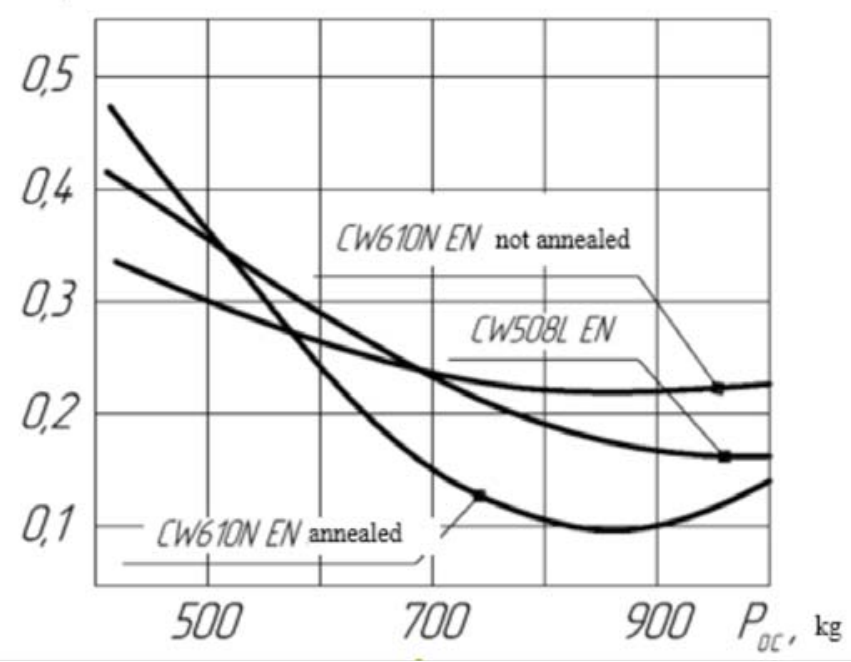

Figure 1: Dependence of increasing product width on the axial compressive force of the knurled package 


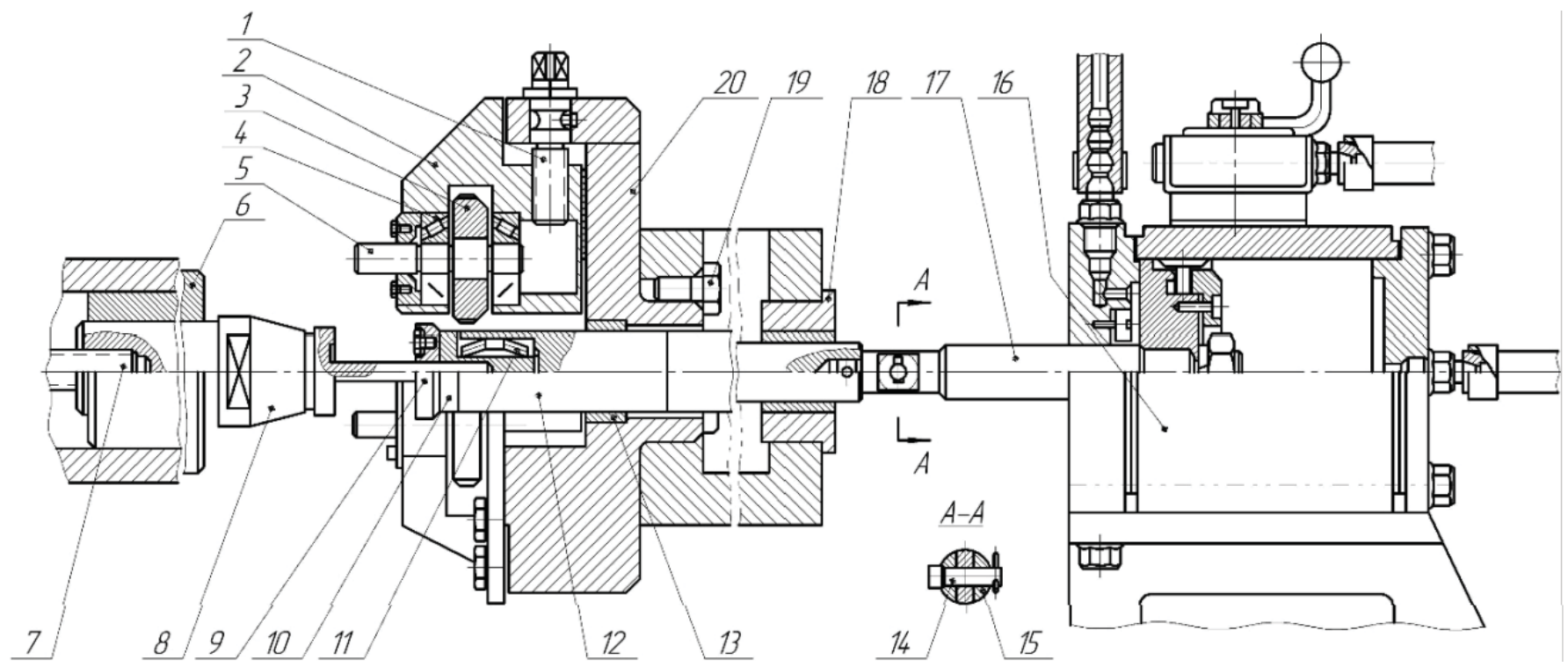

Figure 2: The tool for cold knurling of fins using a capstan lathe

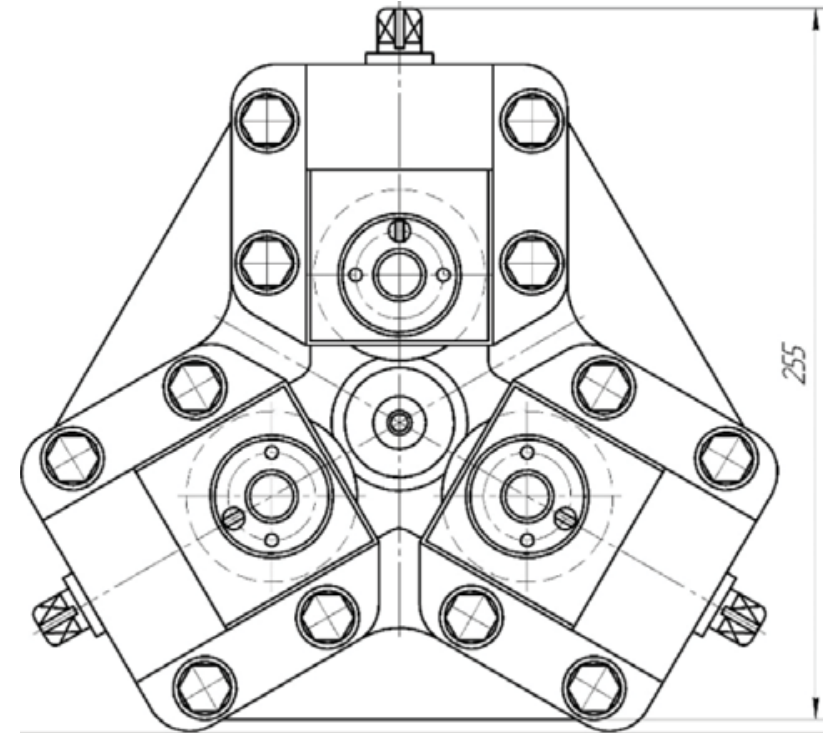

Figure 3: The assembly of the knurling rollers of the tool for cold knurling of fins

most effective solution. In addition to thermos-physical drawbacks, steel has high specific gravity and low corrosion resistance. This factor is restricting.

4. The accumulation of micro defects during operation due to a variable temperature gradient during cooling. The metal has a short heating stage, followed by rapid cooling, mainly by water, which leads to micro-cracks in the contact zone. As a result, the service life is reduced.

5. Reduced contact strength between the fin and the carrier pipe. The next factor in the rapid cooling of the finning welding seam is the appearance of a zone with increased hardness, which leads to a decrease in the welding seam quality and loss in heat transfer efficiency.

The possibility of creating finned surfaces for heat exchangers can be achieved by fundamentally different technologies. However, the effectiveness of their func- tioning will substantially depend on the quality of the surfaces $[20,28,29]$. The modern progressive method is the plastic deformation of metal in a hot or cold state [30]. Plastic deformation of the metal during knurling is associated with the use of significant pressures of the working tool and large radial, circumferential and axial knurling forces [25].

Using the method of plastic deformation of the metal reduces processing waste. In addition, it reduces the consumption of electricity, wear on the tools, and labor costs. Products obtained by this method have a material structure that provides improved mechanical and operational characteristics, compared with products obtained by cutting [31-33]. It should be emphasized that the use of developments that lead even to a slight decrease in metal consumption and the cost of finned surfaces with large requirements for heat exchange equipment across industrial sectors can lead to significant cost savings, expanding the application of resources and energy-saving technologies.

Cold rolling of products with a helical surface is accompanied by a significant deformation of the metal. The maximum allowable deformation during cold rolling is determined by the plastic properties of the billet material [34]. In the manufacture of products with a helical surface, the geometry of the rolled profile depends not only on the geometry of the tool but is also determined by the laws of the peripheral flow of metal in roll passes. During rolling, the billet's metal is deformed by the intake cone of the rolls, the ring or screw gauges of which hamper the axial flow of the metal. The deformation of the billet's metal is the result of radial and axial compression by the protrusions of the roll profile. The form-making of the rolled profile occurs mainly due to the flow of the outer layers of the billet's metal.

The manufacture of capacitors with low fins by cold knurling is not associated with the use of large loads. The high productivity of this process and the relatively small 
production costs make it the most promising. During cold knurling, an increase in the metal durability of the rib's surface layer because of hardening is achieved, and an improved metal texture is provided [31-33]. This significantly increases the wear resistance and strength of the knurled fins compared to milled fins

If various defects often arise on the working surface during hot knurling as a result of heating and cooling the billet such as folds, scales, cracks, temperature stresses, which are primarily responsible for its low fatigue strength - then these defects are absent during cold knurling [30, 35].

During cold knurling, it is possible to obtain - a knurled crown with predetermined geometric parameters attributed to plastic redistribution of the billet metal that takes place because of the working profile of the knurled tool crown. The metal extruded by the knurling roller head flows upward, thus simultaneously forming the fin head due to the feeding the rollers or the billet. In addition, the deformed metal flows axially in both directions, forming a wave ahead of itself, which ultimately flows to both ends.

\section{METHODOLOGY}

Two methods of plastic deformation possess universality and high productivity: rolling with roll-forming tools and rolling in stands with shaped rolls. During rolling, the metal of the billet is deformed by the intake cone of the rolls, the ring or screw gauges of which impede the axial flow of the metal. The deformation of this metal is attributed to radial and axial compression by the protrusions of the roll profile. The form-making of the rolled

$d=m(z-0,14)+2(K \pm \xi m)$

profile mainly occurs due to the flow of the outer layers of the billet's metal. Fins meanwhile, grow asymmetrically. The fin side, which coincides with the axial movement direction of the billet (right side), grows faster than the opposite/left side $[36,37]$. At the intermediate stages of the radial unit compression, the right side has a step, the angle of which differs from that of the rolls' profile.

As demonstrated by the experimental knurling of billets made of brass grades CW610N EN (annealed and not

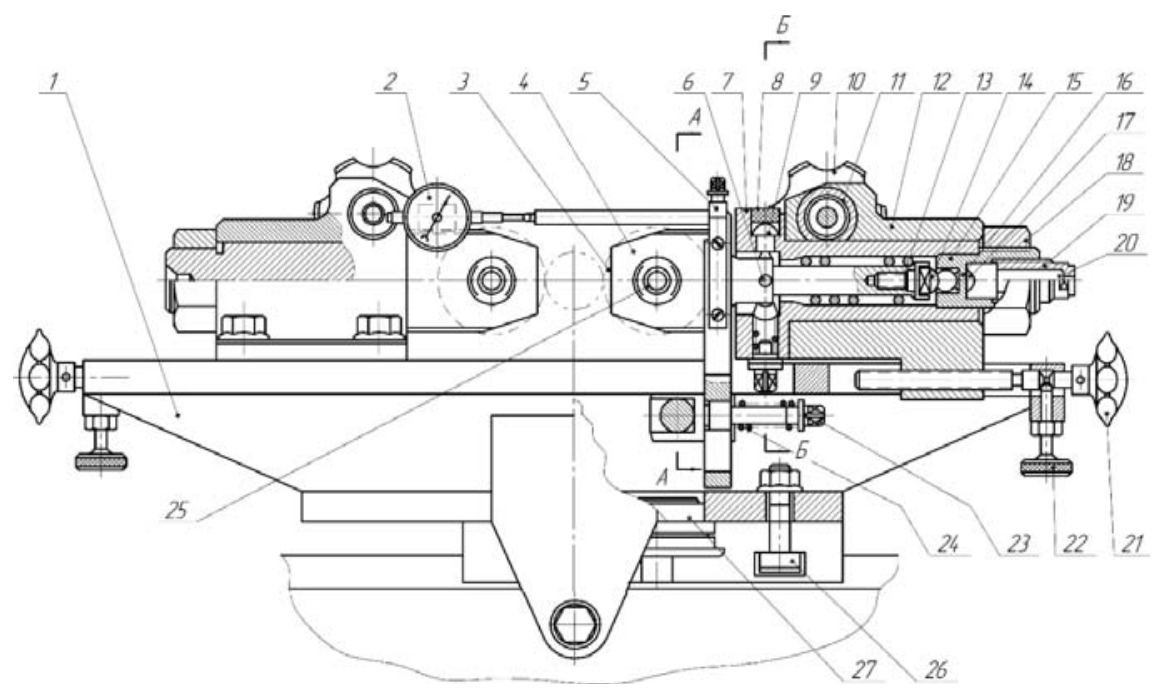

Figure 4: Tool of cold knurling of fins according to the bilateral metal compression scheme (general view)

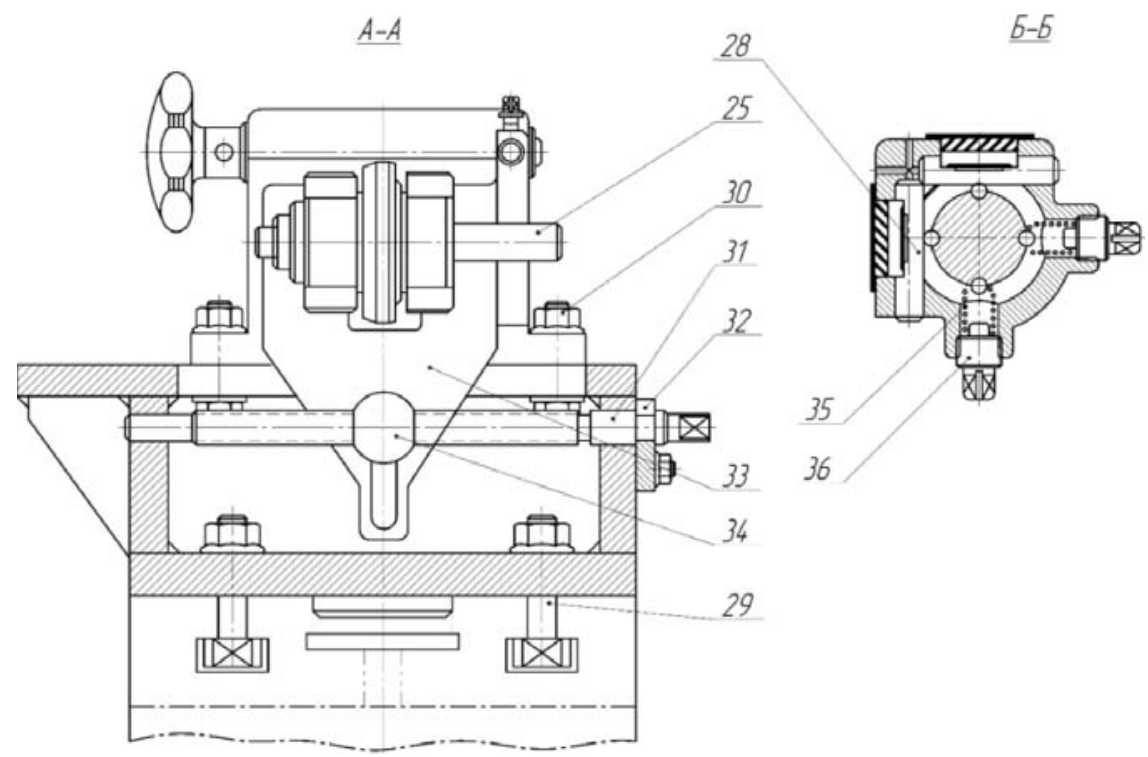

Figure 5: Cross-sections of tools 


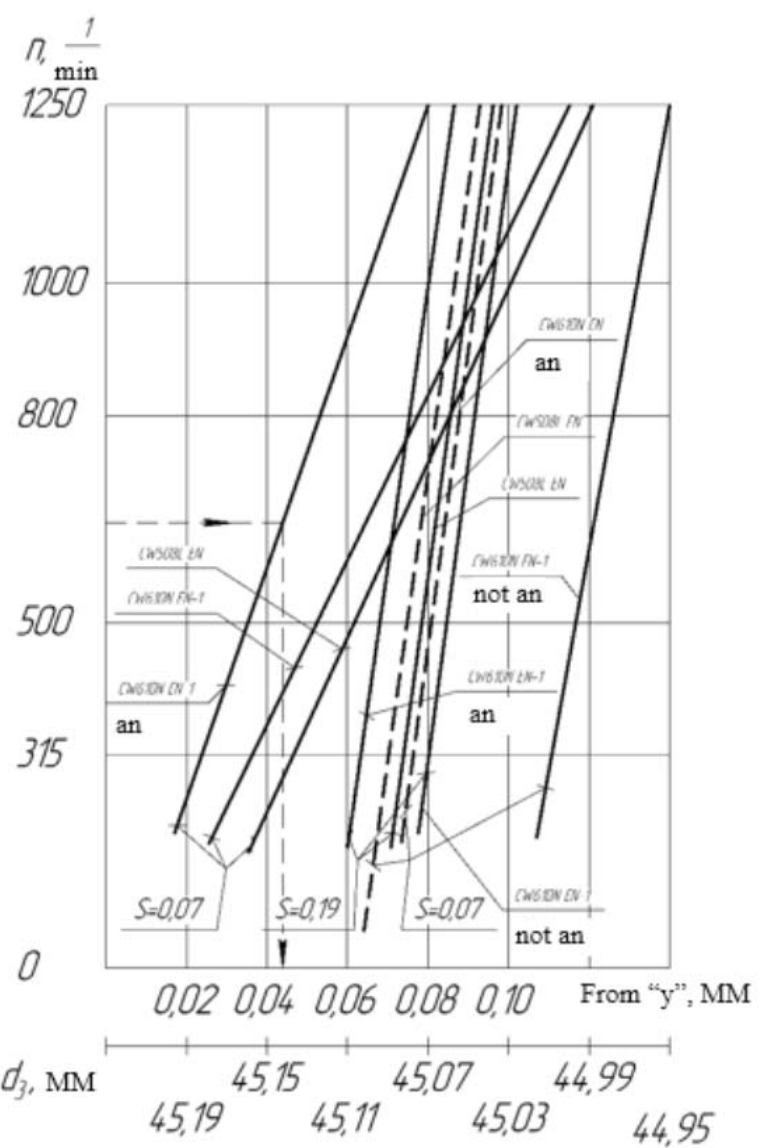

Figure 6: Nomogram for determining the billet's diameter for knurling

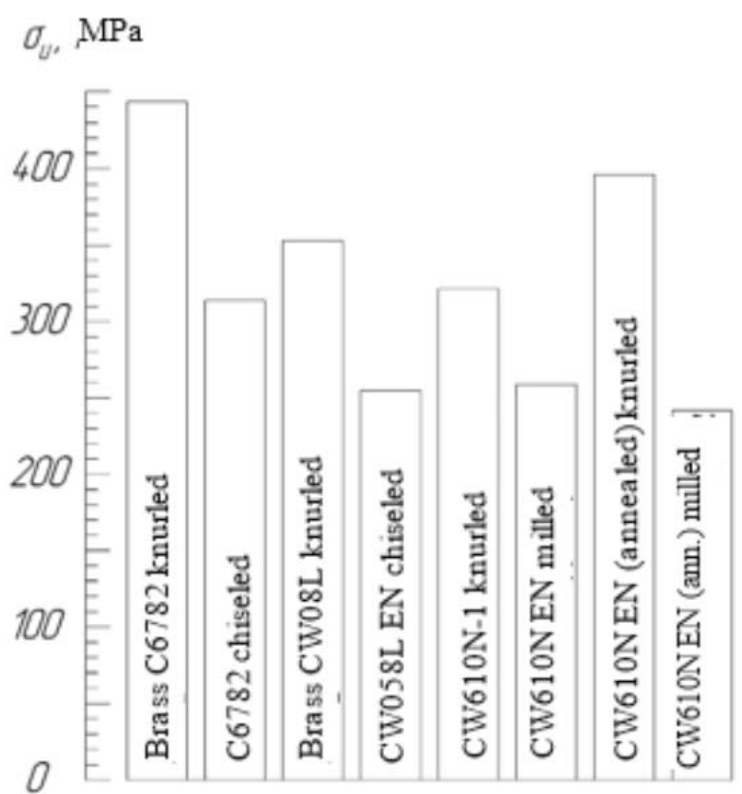

Figure 7: Flexural strength of milled, machined, and knurled fins

annealed) and CW508L EN, it is possible to eliminate flowed metal formation by installing dividing tools from both ends that limit the metal flow. At the same time, it was observed that using additional compression of the knurled billets package with an axial force in the range from 60 to $80 \mathrm{~N}$ significantly reduces or eliminates metal outflow at the ends of the billets (see Figure 1). Concurrently, the size of the burrs at the ends directly depends on the axial compression force of the knurled billet package. Figure 1 illustrates the product width increase as $\Delta h=H_{1}-H$ where $\mathrm{H}$ and $\mathrm{H}_{1}$ denote billet width and knurled roll, respectively.

The process of cold knurling of capacitor fins is most rational to carry out on capstan lathes with the help of knurling tools, which operate according to the scheme of three-sided metal compression by three knurled rollers with axial feed, which provides the highest knurling performance [38, 39].

The tool (Figure 2, 3) has increased body rigidity and individual components, while the use of a pneumatic clamping tool allows the axial clamping of a knurling package of billets with great axial forces. There fore, the tool can be used in severe conditions of cold knurling of fins with a low finning height.

The knurling tool housing 20 is installed in the hole of lathe's machining turret and is attached to it by four bolts 19. Three knurling heads 2 are installed in three symmetrically arranged radial guides, in the openings of which on the rolling bearings 4 and the rollers 5 three knurling rollers 3 are installed. Each knurling head is attached to the tool body with four bolts.

Radial movement of the knurling heads when adjusting the tool is carried out by stop screws 1 , which, besides, prevent radial wipping of the heads under the action of knurling forces. In the inner bore of the knurling tool casing, sleeves 12 with a rotating heel 10 are installed in the bushings 13 and 18, which serves to compress the knurled package of billets.

To ensure the flow of the deformed metal in the radial direction and to limit its undesirable flow in the axial direction, an axial clamp of the billet package is provided with a pneumatic cylinder. When the piston stroke is up to $50 \mathrm{~mm}$ and the air pressure in the network is $4 \mathrm{~kg} /$ $\mathrm{cm} 2$, a force of $420 \mathrm{~kg}$ is provided on the rod. When the air pressure in the network exceeds $6 \mathrm{~kg} / \mathrm{cm} 2$, the force on the rod exceeds $600 \mathrm{~kg}$.

The nature of the deformed metal flow during the cold knurling of the capacitor fins is significantly influenced by the axial, radial, and circumferential components of the cold knurling force. In this regard, it is very important to know the influence of each of them on the nature of the flow of a deformable metal. A tool for cold knurling of fins was designed to determine the value of these components. It was manufactured according to the two-sided compression of metal by two symmetrically located knurling rollers (Figure 5,6 ). One of the two knurling heads is a three-component dynamometer. A free-floating tool holder with a knurling roller is mounted on the sleeve, where three strain pins with wire strain gauges are located. Balls installed in the head help in transferring the forces arising during knurling to the load cells. The values of the components of these forces are 
recorded using an oscilloscope-recorder.

The knurling tool (see Figures 4,5) consists of a rigid support housing 1, in the radial grooves of which are attached to two power housings 12 with eight bolts (it. 30). In the internal bore of the housing, strain pins 8, 16 and 28 with strain gauges 9 and 17 are installed in a power sleeve. The holder 4 with the knurled roller 3 mounted on the shaft 25 in the rolling bearings, is located inside the power sleeve, fixed by a nut 18 . The floating support 14 , located in the sleeve 15, allows for providing three degrees of freedom of the head, and the spring $13 \mathrm{cre}$ ates a constant clamp support 14 to the load cell 16 . The amount of clamping force is regulated by nut 19. Balls 6 transfer the circumferential and axial components of the knurling forces to the tensile pins. The buffer tool (spring 35 and nut 36) provides a constant contact of the balls and pins. Adjusting the size of the adjustment is made by a screw 21 , which is locked by a screw 22 . A design feature of the knurling tool is the ability to knurl capacitor fins on it with a helix angle of up to $\beta= \pm 45^{\circ}$. The buffer tool (parts 23, 24, 34) provides the powerhead supply in three required planes at knurling. The knurling tool is mounted on a lathe instead of a tool holder, centered by a sleeve 27 , and secured with four bolts 26 and nuts 25. To isolate the sensor zone from the coolant, moisture insulation is provided (parts 7,20). An indicator tool (parts 2 and 5) is used to determine the total amount of clamping of the rolled-out heads y arising due to large knurling forces, as well as the elasticity of the part - tool - adaptation - lathe system.

The fins made of brass CW610N EN - 1 (annealed) and CW508L EN, as well as bronze AERIS 1355, were subjected to cold knurling. Knurled rollers had a purity of working profiles within 9-10 classes. The wipping value $y$ in the process of cold knurling depends on the rigidity of the machine-tool system and is in the following range: 0.03-0.09 $\mathrm{mm}$ for brass CW610N EN - 1 annealed; 0.02-0.13 mm - for brass CW610N EN - 1 not annealed; 0.04-0.12 mm - for brass CW610N EN.

Given the wipping value $y$ and depending on the cold knurling modes, it is possible to determine the billet diameter for knurling (Figure 7). It can also be calculated theoretically by the formula (1):

where $m$ is the normal fin package; $z$ is the number of the knurled fins; $K$ is the allowance of the external diameter of the knurled surface $K=(0,4-0,5) m$; $\xi$ is the correction coefficient. The tolerance on the knurling diameter is $\mathrm{d}= \pm 0,01 \mathrm{~mm}$, and on the radial runout of the outer billet's diameter $\mathrm{d}$ should not exceed $0.01 \mathrm{~mm}$.

The results of comparative tests for the bending strength of milled, machined and knurled fins are shown in Figure 7. As can be seen from the figure, the bending force for knurled fins was $50-60 \%$ higher than for fins obtained by cutting methods. Experimental knurling confirmed that the strength of the fins with this method increases on average by $25-40 \%$ [40].

\section{DISCUSSION}

Cold plastic deformation has a significant effect on the physicomechanical properties, macro- and microstructure of the treated metal. Because of cold deformation, the initial metal, which had properties that are approximately the same in different directions and randomly oriented structure, receives a directionally oriented structure of a fibrous nature and increased anisotropic mechanical characteristics. The change in the properties of the metal depends on the degree of plastic deformation, with an increase in which all the characteristics of the metal resistance to deformation increase, namely, strength, hardness, and yield of metal increase. Simultaneously, the plasticity values decrease, which are elongation and toughness. The influence of cold plastic deformation on the surface quality of parts is especially significant.

When rolling the fins, a significant change in the structure of the outer layer of the billet's metal occurs. The structure gets a fibrous structure; metal fibers are oriented along with the worm profile and are highly densified in the cavity. At the recommended fins rolling modes, no defects such as folds, back fins, etc. are observed. Cavity opening or discontinuities in the axial zone of the rolled fin are possible when heating the billet for rolling over its entire cross-section and applying additional compression along the billet's diameter with a finally formed profile. In this case, the metal pressure on the rolls increases rapidly and, in some cases, a discontinuity of the base metal appears or a cavity is opened. Discontinuities and cavity opening are also facilitated by an increase in radial single compressions, an increase in the heating temperature of the billet during knurling, and an increase in the rolls' width. Due to the fins' knurling, metal hardening occurs over the entire cross-section of the fins' profile. This is because the conditions of the fins rolling process are similar to those of the thermomechanical processing of metals.

\section{CONCLUSIONS}

The manuscript proposes the design of the tool for determining the forces acting in the process of cold knurling and investigates the effect of forces on the characteristics of manufactured finned surfaces. The authors tested the developed tool and determined, with its help, the dependence of the increment of the product width on the axial compression force during knurling. Fins made from various grades of brass were subjected to cold knurling. The authors carried out comparative tests of knurled, milled, and machined samples and fins. It has been shown that an important feature of cold-knurled capacitor fins is the formation of a reinforced textured structure over the entire cross-section, while the milled fins have no fibrous structure. Hardening of the surface layer during knurling due to deformation and the fibrous structure of the metal structure increase the operational strength under cyclic loads by an estimated 1.2 times compared with machine cutting. 


\section{ACKNOWLEDGEMENTS}

Some results of this manuscript were Some results of this manuscript were obtained as part of the work under the Agreement on the provision of subsidies from 13 December 2019 No. 75-15-2019-1941 (agreement internal number 05.607.21.0321) on the topic: "Development of design and technological solutions for modular pre-fabricated transmission line towers with integrated systems for continuous digital monitoring of the condition and thermal stabilization of soil to meet the needs of the Arctic regions and the Far North" with the Ministry of Science and Higher Education of the Russian Federation. The unique identifier of the applied research (project) is RFMEFI60719X0321.

\section{REFERENCES}

1. Hakansson, H. (2015). Industrial Technological Development. Routledge Revivals, London. doi:10.4324/9781315724935.

2. Hitomi, K. (2017). Manufacturing Systems Engineering. Routledge, London. doi:10.1201/9780203748145.

3. Zheng, D. (2015). Industrial Engineering and Manufacturing Technology. Proceedings of the 2014 International Conference on Industrial Engineering and Manufacturing Technology (ICIEMT 2014), July 1011, 2014, Shanghai, China. doi:10.1201/b18144.

4. Kopp, R. (1996). Some current development trends in metal-forming technology. Journal of Materials Processing Technology, 60(1-4), 1-9. doi: 10.1016/0924-0136(96)02301-1.

5. Semenov, A.B., Muranov, A.N., Kutsbakh, A.A., Semenov, B.I. (2017). Injection molding of structured multiphase materials. RUDN Journal of Engineering Researches, 18(4), 407-425. doi: 10.22363/23128143-2017-18-4-407-425.

6. Wais, P. (2012). Fin-Tube Heat Exchanger Optimization. Heat Exchangers - Basics Design Applications. InTech, Rijeka. doi:10.5772/33492.

7. Salunke, K.A., Lambhate, V., Jadhav, U., Kumbhar, S. (2016). Optimization of Pipe Finning Process with Engineering Principles. International Journal of Science and Research (IJSR), 5(3), 270-272. doi: $10.21275 / v 5 i 3 . n o v 161849$.

8. Kocurek, R., Adamiec, J. (2013). Manufacturing Technologies of Finned Tubes. Advances in Materials Sciences, 13(3). doi: 10.2478/adms-2013-0009.

9. Huang, H., Ji, C., Yang, Z., Yan, M. (2017). Implementation and forming mechanism of the solid-liquid cast-rolling bonding (SLCRB) process for steel/ Al clad pipes. Journal of Manufacturing Processes, 30, 343-352.

10. Huang, H. (2017). Research on Cast-rolling Force Calculation Model in Solid-liquid Cast-rolling Bonding (SLCRB) Process of Bimetallic Clad Pipe. Journal of Mechanical Engineering, 53(10), 10. doi: 10.3901/jme.2017.10.010.
11. Semenov, A.B., Kutsbakh, A.A., Muranov, A.N., Semenov, B.I. (2019). Metallurgy of thixotropic materials: the experience of organizing the processing of structural materials in engineering Thixo and MIM methods. IOP Conference Series: Materials Science and Engineering, vol. 683, 012056. doi:10.1088/1757-899x/683/1/012056.

12. Saha, S.K., Ranjan, H., Emani, M.S., Bharti, A.K. (2019). Internally Finned Tubes and Spirally Fluted Tubes. SpringerBriefs in Applied Sciences and Technology, 85-126. doi: 10.1007/978-3-030-20748-9_6.

13. Naphon P. (2007). Thermal performance and pressure drop of the helical-coil heat exchangers with and without helically crimped fins. International Communications in Heat and Mass Transfer, 34(3), 321330. doi: 10.1016/j.icheatmasstransfer.2006.11.009.

14. Fan, L., Gao, Y., Li, Q., Xu, H. (2012). Quality control on crimping of large diameter welding pipe. Chinese Journal of Mechanical Engineering, 25(6), 12641273. doi: 10.3901/cjme.2012.06.1264.

15. Merkulov, D.V. (2008). Pipe rolling in helical-rolling mills without a guide system. Steel in Translation, 38(7), 580-584. doi: 10.3103/s096709120807022x.

16. Vydrin, A.V., Shirokov, V.V. (2011). Speed simulation of continuous pipe rolling. Steel in Translation, 41(2), 140-142. doi: 10.3103/s0967091211020215.

17. Sawicki, S., Dyja, H. (2012). Theoretical and Experimental Analysis of the Bimetallic Ribbed Bars Steel - Steel Resistant to Corrosion Rolling Process. Archives of Metallurgy and Materials, 57(1). doi: 10.2478/v10172-011-0153-2.

18. Sadeghi, M. (2017). High frequency resistance welded finned tubes technologies in heat recovery steam generator boilers. Journal of Environmental Friendly Materials, 1(1), 46-57.

19. Wang, S., Cheng, S., Yu, H., Rao, Z., Liu, Z. (2013). Experimental investigation of $\mathrm{Al}-\mathrm{Cu}$ composed tube-fin heat exchangers for air conditioner. Experimental Thermal and Fluid Science, 51, 264-270. doi: 10.1016/j.expthermflusci.2013.08.007.

20. Carija, Z., Frankovic, B., Percic, M., Cavrak, M. (2014). Heat transfer analysis of fin-and-tube heat exchangers with flat and louvered fin geometries. International Journal of Refrigeration, vol. 45, 160167. doi:10.1016/j.jirefrig.2014.05.026.

21. Galushchak, I. (2017). Experimental investigation of heat transfer in interfin channels of punched spiral tube finning. Technology Transfer: Fundamental Principles and Innovative Technical Solutions, 1214. doi: 10.21303/2585-6847.2017.00473.

22. Filippov, E.B., Cherepennikov, G.B., Leshchenko, T.G. (2010). A numerical study of the thermal efficiency of a tubular heating surface with split spiral-tape finning. Thermal Engineering, 57(7), 598-602. doi: $10.1134 / \mathrm{s} 0040601510070116$ 
23. Kuzma-Kichta, Y.A., Savel'ev, P.A., Koryakin, S.A., Dobrovol'skii, A.K. (2007). Studying of heat-transfer enhancement in tubes with screw knurling. Thermal Engineering, 54(5), 407-409. doi: 10.1134/ s0040601507050138.

24. Paquet, A. (1993). Comparison of Brazing Processes for Aluminum Heat Exchanger Manufacturing. SAE Technical Paper Series. doi: 10.4271/931093.

25. Jiang, Z.Y. (2011). Mechanics of cold rolling of thin strip. Numerical analysis-Theory and application, IntechOpen, Rijeka, 439-462. doi:10.5772/23344.

26. Afanasyev, A.E., Kargin, V.R., Kargin, B.V. (2016). Force conditions for light-alloy spiral-finned drill pipe extrusion. Izvestiya Vuzov Tsvetnaya Metallurgiya (Proceedings of Higher Schools Nonferrous Metallurgy), (2), 58-63. doi: 10.17073/0021-3438-2016-258-63.

27. Wagner, J.R., Mount, E.M., Giles, H.F. (2014). Pipe and Tubing Extrusion. Extrusion, 573-583. doi: 10.1016/b978-1-4377-3481-2.00050-8.

28. Wang, F., Liang, C., Yang, M., Fan, C., Zhang, X. (2015). Effects of surface characteristic on frosting and defrosting behaviors of fin-tube heat exchangers. Applied Thermal Engineering, vol. 75, 11261132. doi:10.1016/j.applthermaleng.2014.10.090.

29. Kim, K., Lee, K.-S. (2013). Frosting and defrosting characteristics of surface-treated louvered-fin heat exchangers: Effects of fin pitch and experimental conditions. International Journal of Heat and Mass Transfer, vol. 60, 505-511. doi:10.1016/j.ijheatmasstransfer.2013.01.036.

30. Sakai, T., Belyakov, A., Kaibyshev, R., Miura, H. (2014). Dynamic and post-dynamic recrystallization under hot, cold and severe plastic deformation conditions. Progress in Materials Science, 60, 130-207. doi: 10.1016/j.pmatsci.2013.09.002.

31. Bower, A.F., Johnson, K.L. (1989). The influence of strain hardening on cumulative plastic deformation in rolling and sliding line contact. Journal of the Mechanics and Physics of Solids, 37(4), 471-493. doi:10.1016/0022-5096(89)90025-2.

32. McDowell, D.L., Moyar, G.J. (1990). Effects of non-linear kinematic hardening on plastic deformation and residual stresses in rolling line contact. Mechanics and Fatigue in Wheel/Rail Contact, 19-37. doi:10.1016/b978-0-444-88774-0.50006-7.
33. Yoshimi, T., Matsumoto, S., Tozaki, Y., Yoshida, T., Sonobe, H., Nishide, T. (2009). Work Hardening and Change in Contact Condition of Rolling Contact Surface with Plastic Deformation. Tribology Online, vol. 4, no. 1, 1-5. doi:10.2474/trol.4.1.

34. Johnson, K.L. (2000). Plastic Deformation in Rolling Contact. Rolling Contact Phenomena, 163-201. doi:10.1007/978-3-7091-2782-7_3.

35. Liu, B., Tang, C.L., Gu, T.Q. (2014). A Method to Avoid Strip Breakage for Thin Strip Steel in Cold Rolling. Advanced Materials Research, 10041005, 1211-1215. doi: 10.4028/www.scientific.net/ amr.1004-1005.1211.

36. Jiang, Z.Y., Du, X.Z., Du, Y.B., Wei, D.B., Hay, M. (2010). Strip Shape Analysis of Asymmetrical Cold Rolling of Thin Strip. Advanced Materials Research, 97-101, 81-84. doi: 10.4028/www.scientific.net/ amr.97-101.81.

37. Aljabri, A., Jiang, Z.Y., Wei, D.B. (2014). Analysis of Thin Strip Profile during Asymmetrical Cold Rolling with Roll Crossing and Shifting Mill. Advanced Materials Research, 894, 212-216. doi: 10.4028/www. scientific.net/amr.894.212.

38. Zhang, P., Kou, S., Lin, B., Wang, Y. (2014). Optimization for radial knurling connection process of assembled camshaft using response surface method. The International Journal of Advanced Manufacturing Technology, 77(1-4), 653-661. doi: 10.1007/s00170-014-6486-z.

39. Feng, C.-X.J., Wang, X.-F. (2004). Data mining techniques applied to predictive modeling of the knurling process. IIE Transactions, 36(3), 253-263. doi: 10.1080/07408170490274214.

40. Song, M., Liu, X.H., Tang, D.L. (2014). Texture Evolution of Commercially Pure Copper during Ultra-Thin Strip Rolling. Advanced Materials Research, 941-944, 1532-1536. doi: 10.4028/www.scientific.net/amr.941-944.1532.

Paper submitted: 20.03.2020.

Paper accepted: 30.03.2020.

This is an open access article distributed under the CC BY 4.0 terms and conditions. 